\title{
SAUTCHUK, João Miguel. 2012. A poética do improviso: prática e habilidade no repente nordestino
}

\author{
Rafael Antunes Almeida
}

\section{Q OpenEdition}

1 Journals

Edição electrónica

URL: http://journals.openedition.org/aa/720

DOI: $10.4000 /$ aa. 720

ISSN: 2357-738X

Editora

Programa de Pós-Graduação em Antropologia Social (UnB)

\section{Edição impressa}

Data de publição: 1 junho 2014

Paginação: 255-258

ISSN: 0102-4302

\section{Refêrencia eletrónica}

Rafael Antunes Almeida, «SAUTCHUK, João Miguel. 2012. A poética do improviso: prática e habilidade no repente nordestino», Anuário Antropológico [Online], v.39 n. 1 | 2014, posto online no dia 01 outubro 2014, consultado o 28 abril 2021. URL: http://journals.openedition.org/aa/720 ; DOI: https://doi.org/ $10.4000 /$ aa. 720

Este documento foi criado de forma automática no dia 28 abril 2021.

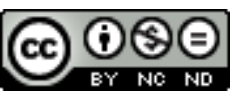

Anuário Antropológico is licensed under a Creative Commons Atribuição-Uso Não-Comercial-Proibição de realização de Obras Derivadas 4.0 International. 


\title{
SAUTCHUK, João Miguel. 2012. A poética do improviso: prática e habilidade no repente nordestino
}

\author{
Rafael Antunes Almeida
}

\section{REFERÊNCIA}

SAUTCHUK, João Miguel. A poética do improviso: prática e habilidade no repente nordestino. Brasília: Editora da Universidade de Brasília. 363 pp

1 Jacques Derrida, na conferência intitulada "Penser à ne pas voir" observa que a improvisação consiste em "Pensar sem ver o avanço, sem ver previamente, sem préver". Conquanto, algumas linhas à frente, o filósofo francês parece apontar para uma aporia que a noção de improvisação enseja: "Será que se pode pintar sem pré-ver, sem desígnio, sem design?".

2 A obra assinada por João Miguel Sautchuk, publicada em 2012 pela Editora da Universidade de Brasília e produto de sua tese de doutorado, de algum modo pode ser pensada como um diálogo com a questão assinalada por Derrida, isto é, a dialética entre o instante da criação poética e as suas condições de possibilidade ou, nos termos do autor, entre estrutura e ação (:25). Esta questão, cujo lastro nas ciências sociais é extenso, é trazida à baila por via dos escritos de Pierre Bourdieu concernentes ao tema da práxis, matriz que o conduz a discutir a questão das habilidades dos cantadores e o problema do improviso, que se vê acomodado entre o código e a prática.

A etnografia que permite ao autor se colocar na discussão nuançada acima foi realizada junto a cantadores, apologistas e declamadores de cidades na região Nordeste do Brasil, os quais o antropólogo não só entrevistou, como acompanhou em festivais e cantorias. Ademais do investimento no processo de interpretação dos cantadores acerca de suas próprias atividades - as exegeses "nativas" - João Sautchuk apostou no aprendizado da cantoria como uma "estratégia de pesquisa". 0 último movimento, vale salientar, nesta 
obra é menos uma reedição do já roto tropo do "agir como se fosse nativo" e mais uma dilatação da sensibilidade para os "problemas que ocupam os cantadores". Ainda merece consideração o fato de que a mencionada escolha metodológica está muito bem aclimatada à ambiência conceitual na qual o livro se alberga, a qual prevê que o aprendizado se dá por meio de um processo de incorporação de disposições generativas.

4 Este parece ser exatamente o tema que ocupa Sautchuk no primeiro capítulo, dedicado a explorar o improviso menos como um conjunto de habilidades individuais e antes como um "jogo de disposições interativas" (:45) Tal qualificação na percepção do autor é justa porque os cantadores, diferentemente da modalidade de improviso assistida entre os músicos de jazz, não veem sua atividade como um "impulso de liberdade criativa", mas como um momento de inspiração (:53). A sua atividade é percebida como um "dom divino" (:53), cuja transdução em criação poética se faz em relação a um conjunto de regras - quanto à rima, à oração e à métrica. Tais regras, todavia, se têm uma função restritiva, também abrigam uma função gerativa, haja vista que engendram criações, a exemplo das "orações" - coerência da criação com aquilo que foi cantado anteriormente - que "... impelem o fazer poético para o diálogo..." (:65), ao mesmo tempo em que encerram uma dimensão ética, prevenindo o "uso de versos decorados" pelos cantadores (:65).

5 Entretanto, as habilidades relativas à cantoria não se reduzem ao bom manejo dos três elementos anotados nas linhas acima. No primeiro capítulo, além de uma extensa exploração sobre a rima, a oração e a métrica, Sautchuk também analisa a música, os desafios que timbres de vozes diferentes impõem à relação entre cantadores e o modo como o principal instrumento, a viola, compõe a apresentação da cantoria. Tais considerações, que demonstram um domínio técnico da arte pelo autor - o intervalo entre as páginas 75 e 77, onde se analisam as afinações das cordas e os tons, exige certo conhecimento musical para a compreensão - servem ao propósito de apresentar em que medida os versos devem ser compreendidos diante dos outros recursos presentes. $\mathrm{E}$ sendo o foco neste capítulo o processo de composição poética, o autor também se concentra nos temas recorrentes nos versos. Neste diapasão, o trabalho dito intelectual aparece não apenas como um tema central destes em relação de oposição aos ofícios manuais, como via de regra é pensado como um requisito para que o próprio improviso aconteça. Muito embora, comenta Sautchuk no final do capítulo, o improviso retire as suas condições de possibilidade da interação, de certo "conhecimento prático" e de certa habilidade para se ajustar e se expressar em face do parceiro.

6 Se o capítulo um se dedica a um estudo das técnicas e das habilidades dos cantadores colocando em relevo a relação dialógica entre a atualização pragmática e a preparação que o precede, o capítulo dois consiste em um percurso etnograficamente informado pelo "processo de se tornar poeta". Para tanto, o autor se vale das narrativas pessoais dos cantadores sobre a sua iniciação na arte e, ao mesmo tempo, do seu processo de se fazer como sujeito, na medida em que o modelo de antropologia que inspira Sautchuk deve acompanhar os processos de incorporação por meio da interpretação dos interlocutores de campo sobre o modo como adquiriram este conjunto particular de disposições generativas. No que tange ao tema do aprendizado, o autor marca a distinção entre a familiarização com a métrica - fundamentalmente um processo de incorporação - e a rima, que requer um processo de aprendizagem deliberado. Ainda descreve o seu próprio processo de familiarização estética com o repente, que se deu de 
modo reverso ao dos outros cantadores: teria passado da escrita ao canto e não o contrário.

7 O capítulo três, que leva o título de "A profissão da viola", conduz o leitor a uma análise do campo social no qual estão inseridos os cantadores. 0 mesmo se dá não apenas por meio da participação do antropólogo nos mesmos espaços onde os cantadores transitavam, mas também pela atenção à dinâmica da composição dos versos que, assim como sugere Sautchuk, deixa entrever as distinções frequentemente em jogo, a saber: as oposições entre cantadores de primeira linha e segunda linha, assim como aquilo que as motiva, como a diferença entre ganhos, o traquejo com a norma culta da língua portuguesa, os tipos de convite recebidos e os espaços onde são chamados para cantar. Sautchuk ainda se demora nas estratégias interiores ao campo social para ensejar as referidas distinções, como são a zombaria e a maledicência, e ainda mapeia outros atores que, não ocupando a posição de cantadores, transitam pelo campo, tais quais os apologistas, os promoventes, os realizadores de festivais e os organizadores de cantorias. Os referidos festivais figuram como instâncias de consagração para cantadores afamados, na medida em que "... ajudaram a formar e a reproduzir uma elite da cantoria e exprime[m], de diversas maneiras, a estratificação socioeconômica e de prestígio entre os violeiros" (:234). Ainda no capítulo três se assiste a uma detalhada descrição do processo de "institucionalização" e urbanização da cantoria, em especial ao florescimento dos instrumentos de "controle e reprodução profissionais" (:236).

o capítulo quatro volta-se ao tema das reciprocidades no campo da cantoria. A dinâmica dos pagamentos de cachês, os convites e os vínculos de dependência dos cantadores são o objeto desta parte da etnografia. Em certo sentido, Sautchuk diagnostica que o convite, peça fundamental nestas transações, se, por um lado, encerra sempre uma dimensão comercial, por outro, figura como um tipo de gatilho para o acontecimento de outras trocas. Decerto que este contém uma dimensão de "provocação" - considerando que parece persistir um ethos da disputa na criação poética que tem lugar na cantoria - o seu acontecimento nem sempre denota uma relação harmoniosa entre as partes. Um ponto-chave reconhecido pelo autor na forma como as relações de reciprocidade se dão no campo da cantoria é que o modelo de reciprocidade que aí vigora parece ter componentes diferentes do que se lê nas monografias antropológicas sobre a troca na Melanésia. Nas últimas há uma dialética entre "espontaneidade e obrigação", enquanto entre os cantadores, considera Sautchuk, elas são necessariamente interessadas e obrigatórias.

o capítulo cinco se dedica ao tema da eficácia ritual da cantoria, que se dá pelo “... reconhecimento de padrões comunicativos e da configuração geral da ação" (:278). E estes "padrões comunicativos", primordialmente marcados pela disputa e pelo enfrentamento entre os repentistas, não necessariamente assumem a forma de versos que se colocam na posição de diminuir o parceiro. Esta é apenas uma das modalidades e se posta ao lado de outras, como a exaltação de qualidades pessoais e a tentativa de superação em conhecimento letrado - “... um capital simbólico que se presta ao estabelecimento de distinções sociais..." (:315) - sobre um tema. No que concerne ao tópico da disputa, Sautchuk também o relaciona ao processo de construção da masculinidade entre os cantadores, explorando como o uso de metáforas "marciais" e de enfrentamento sugere certas modalidades de construção da subjetividade.

10 A "Poética do improviso" qualifica-se como uma etnografia densa e bem trabalhada, na qual a dimensão dialógica do trabalho de campo, a profundidade analítica, a 
sensibilidade para a fala dos cantores e um estilo arguto se sobressaem. De acordo com João Miguel Sautchuk, o potencial da etnografia, além de sua contribuição no sentido do detalhamento das dinâmicas dos cantadores, reside no fato de esta ser "... uma via empírica para pensar a questão antropológica da relação entre estrutura e ação" (:336). Acerca deste trabalho, vale ainda notar que, embora haja um comprometimento teórico com a noção de "campos sociais", este movimento não compromete a qualidade da pesquisa, uma vez que as interpretações dos cantadores, apologistas e promoventes sobre as suas próprias práticas mantêm-se como contrapesos em relação à rígida armação conceitual sugerida por Pierre Bourdieu.

\section{AUTORES}

RAFAEL ANTUNES ALMEIDA

PPGAS/UnB 